\title{
A rare cause of systemic hypertension in an African child: Questions
}

Patience Sigwadi* and Gertruida van Biljon

Keywords Hypertensive encephalopathy · Blindness . Hypokalaemic metabolic alkalosis

\section{Case summary}

A female toddler was referred to our hospital with the problem of hypertensive encephalopathy manifesting with convulsions, right hemiparesis and blindness.

She had been well until the age of 17 months when she developed fever and symptoms of an upper respiratory tract infection. Her past medical history was significant only for having been a small for gestational age baby. She weighed $2 \mathrm{~kg}$ at birth after a term, uncomplicated pregnancy. She had achieved her milestones normally up to the age of 12 months. Thereafter her mother noticed that her neurological development was faltering-she was not talking or playing, she was disinterested in her environment and she was unusually irritable. She has no family history of hypertension, heart or kidney disease. She has one healthy sibling.

On physical examination she appeared chronically ill. She was severely stunted (length $72.5 \mathrm{~cm}, Z$ score $<-3 \mathrm{SD}$ )

\footnotetext{
P. Sigwadi

Department of Pediatrics, 1 Military Hospital, Thaba Tshwane, Voortrekker Street,

Pretoria, South Africa

P. Sigwadi (*) G. van Biljon

Department of Pediatrics, Steve Biko Academic Hospital,

University of Pretoria, Private Bag x323, Arcadia, Pretoria 0007,

South Africa

e-mail: lusuno@mweb.co.za

G. van Biljon

e-mail: ida.vanbiljon@up.ac.za
}

and wasted (weight for length $Z$ score $<-3 \mathrm{SD}$ ). Her level of consciousness was depressed. All her pulses were present and normal and there was no radio-femoral delay. Her blood pressure was $148 / 92 \mathrm{~mm} \mathrm{Hg}$ and was elevated in all four limbs. She had puffy eyes, but no pedal or sacral oedema. She was clinically anaemic and mildly dehydrated. She did not have any lymphadenopathy. There were no café au lait spots, no malar rash and no evidence of vasculitis. The left precordium was bulging. The apex was heaving in the fifth intercostal space, displaced laterally. The second heart sound was loud. There was no murmur over the heart, the subclavian or carotid vessels, over the inter-scapular area or abdominal aorta. There was weakness of the left arm and leg, and all tendon reflexes were markedly brisk. She had complete loss of vision, but her other cranial nerves were intact. Fundoscopy revealed retinal haemorrhages, but no papilloedema.

Laboratory investigations revealed the following information: she had a hypokalaemic metabolic alkalosis; potassium was $2.8 \mathrm{mmol} / \mathrm{l}$ and bicarbonate was $30 \mathrm{mmol} / \mathrm{l}$. The serum sodium, chloride, urea and creatinine levels were normal. The full blood count showed a hypochromic microcytic anaemia, with haemoglobin of $9.4 \mathrm{~g} / \mathrm{dl}$ [normal 11.1-14.7 g/dl, mean corpuscular volume of $65.9 \mathrm{fl}$ (normal 70-86 fl) and mean corpuscular haematocrit of $20.8 \mathrm{pg}$ (normal $23-31 \mathrm{pg}$ )]. The differential white cell count was normal. Further investigations showed a suppressed plasma immuno-reactive renin of $<1.8$ $\mathrm{mIU} / \mathrm{l}$ (normal 5.4-28.8 mIU/l) and aldosterone level of $<31$ $\mathrm{pmol} / 1$ (normal $28-666 \mathrm{pmol} / 1$ ). The urine potassium was $21.7 \mathrm{mmol} / \mathrm{l}$, urine sodium was $<10 \mathrm{mmol} / \mathrm{l}$ and urine chloride was $20 \mathrm{mmol} / \mathrm{l}$. The urine protein creatinine ratio was $0.23 \mathrm{~g} / \mathrm{mmol}$ (normal $<0.02 \mathrm{~g} / \mathrm{mmol}$ ). Steroid chromatography excluded endocrine causes of hypertension associated with hypokalaemic metabolic alkalosis.

The kidney sonography showed normal-sized kidneys for her length of $72.5 \mathrm{~cm}$ (right $6.1 \times 3.1 \mathrm{~cm}$, left $5.8 \times 3 \mathrm{~cm}$ ), with decreased cortico-medullary differentiation. Renal 
artery stenosis was excluded on renal Doppler ultrasound. The chest X-ray revealed cardiomegaly and the electrocardiograph, left ventricular hypertrophy. The computed tomography scan of the brain showed mild cerebral atrophy.

Her blood pressure did not respond to a combination of amlodipine, enalapril, spironolactone, prazosin, atenolol and hydrochlorothiazide.

\section{Questions}

1. What is the differential diagnosis of hypokalaemic metabolic alkalosis in this child?

2. What is the pathogenesis of the hypertension in this patient?

3. What is the treatment of choice for this condition? 